\title{
THE PROFILE OF OCCUPATIONAL STRESS IN A SAMPLE OF HEALTH PROFESSION ACADEMICS AT A HISTORICALLY DISADVANTAGED UNIVERSITY IN SOUTH AFRICA
}

\author{
A. Simons* \\ Department of Psychology \\ e-mail: abigailsimons91@gmail.com

\section{E. Munnik*} \\ Department of Psychology \\ e-mail: emunnik@uwc.ac.za
}

\section{J. Frantz}

Deputy Vice Chancellor Research and Innovation

e-mail: jfrantz@uwc.ac.za

\section{Smith*}

Deputy Dean Research

e-mail: mrsmith@uwc.ac.za

*University of the Western Cape

Cape Town, South Africa

\section{ABSTRACT}

Background: Higher education is a high stress occupation or environment. Academics in health professions are engaged in professional training that adds clinical or profession-specific competencies to general academic and research outcomes. Academics in health professions assume many roles and must remain current in the practise of their professions that increases stress. Studies on occupational stress amongst health professions academics are lacking in the South African context.

Objectives: To assess occupational stress in a sample of Health profession academics at a Historically Disadvantaged Institution (HDI).

Methods: An online survey was conducted with a randomly selected sample of 51 permanent academics. The response rate was 55 per cent after incentives and reminders. Instruments included a demographic questionnaire, Assessing emotions scale and the Sources of Work Stress Inventory. Descriptive statistics, correlation and regression were used to analyse the data. Instruments were reliable with this sample. Ethics clearance was obtained (Reg. No.: 15/4/42) and all ethics principles were upheld. 
Results: The sample was mostly female, and the composition was consistent with the profiles of the faculty, health professions and HDIs. Small effects were reported for associations between demographics, El and Occupational stress. Mixed results were reported for predictive relationships. El and level of education were predictive of certain sources of occupational stress. Conclusion: Transformations and the work environment contributed to academics experiencing occupational stress. The historical apartheid legacies still manifest in patterned ways along gender, race and professional status in the occupational stress academics experience. Health professionals constitute a legitimate subgroup that impacts the experience and management of occupational stress. El is an important factor to consider in the experience and management of occupational stress.

Key words: Occupational stress, Emotional Intelligence, Health Professions, Higher education

\section{INTRODUCTION}

The transformation of higher education institutions and restructuring of the higher education system has been high on the agenda of government since democratization. Higher Education was identified as a sector in need of revision (National Development Plan 2030. 2012). Post 1994 various policies were implemented to drive a knowledge-based economy and an expanded, effective, coherent and integrated higher education system. Key policies included the 10 year innovation plan of the Department of Science and Technology (DST 2007); the Strategic plan for Higher Education (Ministry of Education 2001), and the National Development plan 2030 (National Development Plan 2030 2012). Government is placing the responsibility to produce both knowledge and knowledge producers on academics (Waghid 2002). Thus, change and transformation are leading forces that are driving a new education landscape for South African higher education. Policy becomes a contributing factor towards the dissatisfaction experienced among academics in the context of post-1994 transformational policy changes (Pienaar and Bester 2009).

HDIs face a number of interrelated challenges post-1994. These included redefining their missions and functions; identifying specialised and niche teaching and research programmes, and building academic, planning and managerial capacity (Bozalek and Boughey 2012). A differential pattern to qualifications was identified where HDI faculty were less qualified than Historically White University (HWU) faculty in 1992 and this trend continued decades later (Bozalek and Boughey 2012). The divide in the higher education system resulting from Apartheid has proven hard to eradicate. Thus, the global challenges in the transformation of higher education are exacerbated in South Africa given the changes observed and legislated during the last two decades (Hay and Monnapula-Mapesela 2009). HDIs represent a subgroup in Higher Education faced with unique challenges and should be studied separately to gain 
greater insight into how general concerns in Higher Education present at these institutions.

The merging of higher education institutions intended to close the gap between HDIs and HWUs. HDIs that remained independent, such as the University of the Western Cape (UWC), continue to experience pressures related to overcoming the historical issues raised above in addition to competing with HWUs for resources and to deliver vastly revised outcomes increases exponentially for staff at HBUs (Mapesela and Hay 2006).

Work-related factors cause occupational stress which has consequences for the work situation. Therefore, occupational stress stems from a number of work-related pressures and one's inability to cope or lack of control over one's job (Rosenthal and Alter 2012). The transformation in higher education has become a leading cause of occupational stress among academics (Kotecha, Ukpere and Geldenhuys 2014). The responsibilities of academics expand in response to increased demands from university administration, research councils and government (Gornall and Salisbury 2012). Academics must improve the quality of their teaching, improve throughput rates and ensure the employability of graduates (Barkhuizen and Rothmann 2008). Academics must produce good quality research, supervise student research, attract external funding, and engage in various administrative duties (Zábrodská et al. 2018). The multiple roles of academics result in high levels of occupational stress (Frantz and Smith 2013). Occupational stress is a more prominent feature of the global academic profession (Fako 2010).

Excessive work overload, work-life imbalances, work relationships, control, communication and job security were sources of occupational stress experienced by academics (Tytherleigh et al. 2005). Occupational stressors have debilitating effects on the individual (Darabi, Macaskill and Reidy 2017) and organisational (Bauwens et al. 2017) outcomes. Most research on occupation stress in academics was conducted in developed countries (Kinman and Jones 2003).

Studies conducted in Africa demonstrated that teaching at university level is a high stress occupation. The increased intake of students with no expansion of university facilities was the main stressor reported among lecturers (Atindanbila 2011). Thus, lecturer-student ratio results in work overload that in turn creates a stressful work environment. Teaching load and professional distress were the second and third highest sources of stress reported. Academic staff reported attaining career aspiration, poor working conditions, career development, work overload and inadequate resources as the most stressful factors experienced (El-Sayed, ElZeiny and Adeyemo 2014).

South African academics reported pressure to produce more research outputs, bigger classes and postgraduate supervision loads as sources of stress (Bezuidenhout and Cilliers 
2010). Increased levels of occupational stress, related to work overload, work-life balance and pay and benefits, were reported in the South African context (Barkhuizen and Rothmann 2008). Early post-democracy research documented that stress left unmanaged lead to burnout in academics (Blix et al. 1994).

Academics within health professions continue as clinical practitioners in order to remain current in clinical expertise and enhance supervision capacity required for the training of health profession students (Du Plessis, Du Plessis and Saccaggi 2013). Health professionals must engage at intense levels of personal and emotional contact that can be stressful. Thus, research into academic occupational stress remains a focus for further research in South Africa that reflect the more recent changes in the academic landscape (Barkhuizen and Rothmann 2008).

Gillespie et al. (2001) reported that research on how academics cope with occupational stress focused on styles of coping including recognition and achievement, high morale, the support from co-workers and management, and flexible working conditions. Several factors that can significantly impact the extent to which one copes with occupational stress have been identified including, but not limited to personality, the nature of the stressful event, the social context within which coping occurs and emotional intelligence (Montes-Berges and Augusto 2007; Carver and Connor-Smith 2010). Components of EI could be seen as moderators which could help academics to cope with occupational stressors (Mark and Smith 2012).

EI is the capacity to genuinely recognise one's own emotions, to discern between what you are feeling and how others are feeling, and to use that information to guide one's thoughts and actions (Fernandez 2007). EI has four components namely, 1) perceiving emotion, 2) using emotion, 3) understanding emotion and 4) managing emotions (Jude 2011). Individuals who are capable of regulating their emotional states have been found to be healthier (Pau and Croucher 2003). EI reduces stress and is associated with active coping and better adaptation (MacCann et al. 2011). EI is directly connected to resilience (Gohm, Corser and Dalsky 2005). People with higher EI tend to cope better with emotional demands of stressful situations (Armstrong, Galligan and Critchley 2011).

EI may protect individuals from stress and may enhance human accomplishment and personal well-being (Adeyemo and Ogunyemi 2005). EI can impact academic performance such that people with high EI deal better with stressful events and have better coping skills (Bar-On 2010). The avoidance of stressful encounters; more constructive perceptions and situational appraisals; adaptive management and reparation of emotions; richer coping resources and use of effective and flexible coping strategies were identified as functions of EI (Cherniss 2010). EI is a significant factor influencing occupational stress among academics (Jude 2011). Systematic exploration of EI and occupational stress amongst academics and 
health professionals remain a focus of further research (Por et al. 2011)

To conclude, there is evidence that academics experience significant stress related to changes within higher education, multiple roles and the commitments and responsibilities. There is a small body of literature that reports on coping strategies used by academic staff and provides evidence that emotional intelligence is an important factor associated with stress and coping (Nikolaou and Tsaousis 2002). However, academics at HDIs and in health professions were not prioritized as a target group in research on stress, coping or emotional intelligence. There remains a paucity of research on sources of occupational stress amongst academic staff in health professions (Du Plessis et al. 2013). Similarly, research is needed on emotional intelligence as a facilitator to cope with occupational stress (Adeyemo and Ogunyemi 2005). The majority of studies on stress, coping and EI were conducted in developed countries. Therefore, there is a gap within low- and middle-income countries (LMIC) such as South Africa underscoring contextual factors. In particular, the relationships between Occupational Stress and EI in Health professions academics at HDIs remain a focus for further research. This manuscript reports on a study aimed at determining the relationship between occupational stress and emotional intelligence in a sample of health profession academics at an HDI.

\section{METHODS}

\section{Aims and objectives}

The aim of this study was to determine the relationship between occupational stress and emotional intelligence in a sample of Health Professions academics.

\section{Research setting}

The identified research setting was a Health Science Faculty at a university in the Western Cape. The Apartheid government established the identified university for sections of the population that were not "White" and was classified as a Historically Disadvantaged Institution (HDI) post-1994 (O’Connell 2011). The identified institution is now classified as a researchintensive university. The identified Health Sciences faculty aims at equipping health professionals with the skills to help transform health and welfare services in South Africa. Professional degree programmes are offered in the faculty that allows graduates to register as professionals with the Health Professions Council of South Africa (HPCSA). The faculty is comprised of 92 permanent academic staff that formed the sampling frame. The gender composition is predominantly female. 


\section{Design}

A cross-sectional, online survey design was utilised. The survey was hosted on Survey Monkey and was tested for ease of administration and graphic formatting on multiple monitors and software applications. Weekly reminders and lottery incentives were used to increase the initial response rate from 16 per cent $(\mathrm{N}=15)$ to 55 per cent $(\mathrm{N}=51)$. The response rate exceeded the average response rates for surveys and satisfied the recommended target for robust analysis other modes of administration (Williams and Saunders 2011).

\section{Instruments}

1. Demographic Questionnaire. A self-constructed questionnaire was used to measure gender, race, department, years in academia, highest qualification and academic status/ rung.

2. The Assessing Emotions Scale assesses EI along four factors namely, Perception of emotion, Managing own emotions, Managing others emotions and Utilisation of emotion (Schutte et al. 1998). Schutte, Malouff, and Bhullar (2009) reported good reliability. Cronbach alphas of $.86 ; .81 ; .76$ and .78 for Perception of emotion; Managing own emotions; Managing others emotions and Utilization of emotions respectively were reported in the present study.

3. The Sources of Work Stress Inventory (SWSI) consists of the General Work Stress Scale and the Sources of Work Stress Scale that appraises eight sources of work stress (De Bruin and Taylor 2005). Good psychometric properties were reported ranging from .86 to .94 suggesting that the SWSI was suitable for research. High Cronbach alphas were reported for Role ambiguity $(\alpha=.85)$; Tools and equipment $(\alpha=.88)$; Career advancement $(\alpha=$ .89 ); Work/home interface $(\alpha=.85)$; Relationships $(\alpha=.93)$; Job security (Cronbach's $\alpha$ $=.91)$; Lack of autonomy $(\alpha=.92)$, and Workload $(\alpha=.96)$ in the present study.

\section{Analysis}

Data satisfied the assumptions for inferential statistics. Frequencies distributions were used to compile the demographic profile of the participants. Correlations were computed to assess associations between variables and to identify possible covariates for inclusion in subsequent regression analysis. Nine regression models were tested to determine the predictive relationship between EI and Occupational Stress, controlling for identified covariates. 


\section{Ethics}

Project registration and ethics clearance (Reg. No.: 15/4/42) was granted by the Senate Research Committee of UWC. Permission for access was granted by the Registrar and Dean of the identified institution. Eligible participants received an information sheet that summarized what the study entailed, underscored the rights of the researcher and participants, and outlined the risks and benefits of participating. Participants completed consent forms.

\section{RESULTS}

Of the total respondents, 66.7 per cent $(n=34)$ were female and 33.3 per cent $(n=17)$ were male. Ethnic self-identifications were as follows: 33.3 per cent $(n=17)$ self-identified as White, 47.1 per cent $(n=24)$ as Coloured, 7.8 per cent $(n=4)$ as Black, 7.8 per cent $(n=4)$ as Indian and 4 per cent $(n=2)$ as "Other". Respondents ranged in years in academia from 3 to 35 years, with a mean of 13 years, median of 11 years and a mode of 8 years. Of the total respondents 3.9 per cent $(n=2)$ qualified with an Honours degree, 45.1 per cent $(n=23)$ with a Masters degree and 51.0 per cent $(n=26)$ with $\mathrm{PhD}$. With regards to academic status, 5.9 per cent $(\mathrm{n}=$ 3) were Associate Lecturers; 56.9 per cent $(n=29)$ were Lecturers; 21.6 per cent $(n=11)$ were Senior Lecturers; 5.9 per cent $(n=3)$ were Associate Professors, 7.8 per cent $(n=4)$ were Full or Senior Professors, and one omitted this item.

\section{Occupational stress profile}

Table 1: Occupational stress profile for academic staff $(\mathrm{N}=51)$

\begin{tabular}{|c|l|c|c|c|c|c|}
\hline $\begin{array}{c}\text { Rank } \\
\text { order }\end{array}$ & Range & Minimum & Maximum & Mean & $\begin{array}{c}\text { Std. } \\
\text { Deviation }\end{array}$ \\
\hline 1 & Workload & 53 & 27 & 80 & 56.02 & 12.451 \\
\hline 2 & Work/Home Interface & 31 & 38 & 69 & 55.02 & 8.499 \\
\hline 3 & General Work Stress & 42 & 36 & 78 & 53.06 & 9.704 \\
\hline 4 & Role Ambiguity & 23 & 41 & 64 & 51.52 & 5.589 \\
\hline 5 & Relationships & 70 & 0 & 70 & 51.10 & 10.585 \\
\hline 6 & Tools and Equipment & 29 & 37 & 66 & 50.31 & 8.627 \\
\hline 7 & Lack of Autonomy & 56 & 24 & 80 & 47.80 & 11.721 \\
\hline 8 & Career Advancement & 41 & 30 & 71 & 47.16 & 9.313 \\
\hline 9 & Job Security & 36 & 30 & 66 & 44.41 & 9.620 \\
\hline
\end{tabular}

Workload, Work/Home Interface and General Work stress emerged as the top three stressors among academic staff. Job Security produces the least amount of stress among academic staff. The average scores across all the subscales of occupational stress were relatively high and the range of average scores was constricted suggesting that academic staff reportedly experience a 
substantial amount of occupational stress from varied sources with some sources of stress peaking slightly. Scores for relationships as a source of stress were more variable evident in the range (70) that included scores of zero. Role ambiguity has the lowest range indicating less variation.

\section{Emotional intelligence profile}

Table 2: Emotional intelligence profile for academic staff $(\mathrm{N}=51)$

\begin{tabular}{|c|l|c|c|c|c|c|}
\hline $\begin{array}{c}\text { Rank } \\
\text { Order }\end{array}$ & Range & Minimum & Maximum & Mean & $\begin{array}{c}\text { Std. } \\
\text { Deviation }\end{array}$ \\
\hline 1 & Managing Own Emotions & 2 & 3 & 5 & 4.11 & .500 \\
\hline 2 & Perception of Emotion & 2 & 3 & 5 & 3.99 & .587 \\
\hline 2 & Managing Others Emotions & 3 & 2 & 5 & 3.99 & .560 \\
\hline 3 & Utilization of Emotions & 4 & 2 & 5 & 3.92 & .608 \\
\hline
\end{tabular}

Academics' ability to manage emotions within themselves was ranked first. The capacity to perceive emotions and the capacity to manage the emotions of others jointly ranked second. The use of emotions to facilitate cognitive activities such as thinking and problem solving ranked fourth. The truncated ranking and small difference in mean scores indicate that less variance was reported across capabilities.

\section{Correlation between demographics and sources of occupational stress}

Table 3: Correlation matrix for demographic variables and sources of occupational stress $(N=49)$

\begin{tabular}{|l|c|c|c|c|c|}
\hline & Gender & $\begin{array}{c}\text { Years in } \\
\text { Academia }\end{array}$ & $\begin{array}{c}\text { Highest } \\
\text { Qualification }\end{array}$ & Race & $\begin{array}{c}\text { Academic } \\
\text { status }\end{array}$ \\
\hline General Work Stress & -.139 & .035 & -.098 & -.040 & -.047 \\
\hline Role Ambiguity & -.266 & -.119 & -.160 & .110 & -.102 \\
\hline Relationships & -.087 & .087 & -.098 & -.175 & .074 \\
\hline Tools and Equipment & -.031 & $-.294^{*}$ & $-.308^{*}$ & -.202 & $-.328^{*}$ \\
\hline Career Advancement & -.013 & -.170 & $-.311^{*}$ & .237 & $-.335^{*}$ \\
\hline Job Security & -.108 & $-.353^{*}$ & $-.467^{* *}$ & $.306^{*}$ & $-.366^{*}$ \\
\hline Lack of Autonomy & .039 & -.064 & $-.374^{\star *}$ & $.316^{*}$ & -.140 \\
\hline Work/Home Interface & $-.338^{*}$ & -.050 & .057 & -.192 & -.136 \\
\hline Workload & -.116 & .143 & .053 & -.116 & .011 \\
\hline
\end{tabular}

${ }^{*}$ Correlation is significant at the 0.05 level (2-tailed). ${ }^{* *}$ Correlation is significant at the 0.01 level (2-tailed)

A small, inverse correlation between Gender and Work/Home interface tested significant $(r=-.338, p<0.05)$. Female staff were significantly more likely to report stress due to negotiating the work/home interface. A small, inverse correlation between Years in Academia and Tools and Equipment tested significant $(r=-.294, p<0.05)$. Academics who entered 
academia more recently were significantly more likely to experience stress related to the tools and equipment needed to do their job. A small, inverse correlation between Years in Academia and Job Security tested significant $(r=-.353, p<0.05)$. Stress related to job security tended to decrease as the number of years of service increased.

Small, inverse associations between level of qualifications and Tools and Equipment $(r=.308)$, as well as Career Advancement tested significant $(r=-.311, p<0.05)$. Higher qualified academics experienced less stress related to tools and equipment. Similarly, higher qualified academics experienced less stress related to career advancement. A modest inverse correlation tested significant between Level of Qualification and Job Security $(r=-.467$, $\mathrm{p}<0.01)$ and Lack of Autonomy $(r=-.374, p<0.01)$ respectively. Higher qualified academics experience less stress concerning job security. Academics with higher qualifications experience less stress with regards to lack of autonomy.

A small, positive association between Race and Job Security tested significant $(r=.306$, $p<0.05)$. Race was coded such that increases represented moving from White to minority ethnic status. Minority academics experienced higher levels of stress related to job security. A small, positive association between Race and Lack of Autonomy tested significant $(r=.316, p<0.05)$. Minority academic staff experience more stress related to the lack of autonomy.

A small, inverse correlation between Academic Status and Tools and Equipment tested significant $(r=-.328, p<0.05)$. Lower ranked academics experienced more stress related to tools and equipment. Small inverse correlations tested significant between Academic Status and Career Advancement $(r=-.335, p<0.05)$, as well as Job Security $(r=-.366, p<0.05)$ respectively. Academics with lower academic status experienced more stress regarding career advancement and job security.

\section{Correlation between demographic variables and EI}

Table 4: Correlation matrix for demographic variables and emotional intelligence $(N=51)$

\begin{tabular}{|l|c|c|c|c|c|}
\hline & Gender & $\begin{array}{c}\text { Years in } \\
\text { Academia }\end{array}$ & $\begin{array}{c}\text { Highest } \\
\text { Qualification }\end{array}$ & Race & $\begin{array}{c}\text { Academic } \\
\text { Status }\end{array}$ \\
\hline Perception of Emotion & .040 & .029 & -.215 & .147 & -.120 \\
\hline Managing Own Emotions & $.305^{*}$ & .114 & -.155 & $.400^{* *}$ & -.095 \\
\hline Managing Others Emotions & .004 & .009 & $-.402^{* *}$ & $.326^{*}$ & -.166 \\
\hline Utilization of Emotions & .087 & -.045 & -.125 & .092 & -.194 \\
\hline
\end{tabular}

${ }^{*}$ Correlation is significant at the 0.05 level (2-tailed).

${ }^{* *}$ Correlation is significant at the 0.01 level (2-tailed).

A small, positive association between Gender and Managing own Emotions tested significant $(r=.305, p<0.05)$. Female academics were more likely to manage their own emotions. A small, inverse correlation between Level of Qualification and Managing Others Emotions tested 
significant $(r=-.402, p<0.05)$. Higher qualified academics were less likely to manage the emotions of others. Conversely, academics with lower qualifications were more likely to manage the emotions of others. A small, positive correlation between Race and Managing Own Emotions tested significant $(r=.400, p<0.05)$. Academics of minority ethnicity were more inclined to manage their own emotions. A small, positive correlation between Race and Managing others Emotions tested significant $(r=.326, p<0.05)$. Academics of minority ethnicities were more likely to manage the emotions of others.

\section{Correlation between sources of occupational stress and EI}

Table 5: Correlation matrix for sources of occupational stress and emotional intelligence $(N=51)$

\begin{tabular}{|c|c|c|c|c|c|c|c|c|c|}
\hline & GWS & RA & R/ships & T\&E & CA & JS & LA & W/HI & $\mathbf{W}$ \\
\hline Perception of Emotion & .193 & .103 & .185 & .007 & .176 & .074 & $.381^{* *}$ & .057 & .249 \\
\hline Managing Own Emotions & -.274 & -.158 & -.011 & -.247 & .123 & .029 & .150 & $-.409 * *$ & -.175 \\
\hline Managing Others Emotions & .091 & .103 & .124 & -.019 & .280 & .145 & $.426^{* *}$ & -.057 & .105 \\
\hline Utilization of Emotions & .170 & .214 & .117 & -.014 & $.295^{\star}$ & .130 & $.441^{* *}$ & .247 & .202 \\
\hline
\end{tabular}

A small, positive correlation between Career Advancement and Utilization of Emotions tested significant $(r=.295, p<0.05)$. Academic staff who are more able to utilize their emotions is significantly more likely to advance in their careers. A small, positive correlation between Lack of autonomy and Perception of emotion tested significant $(r=.381, p<0.01)$. Academics who are less inclined to perceive emotions within themselves and within others are significantly more likely to experience stress related to lack of autonomy.

Moderate, positive correlations tested significant between Lack of Autonomy and Managing others' emotions $(r=.426, p<0.01)$, as well as Utilization of emotions $(r=.441$, $p<0.01)$ respectively. Academics who are more inclined to manage the emotions of others are significantly more likely to experience stress related to lack of autonomy. Similarly, academics who are more inclined to use emotions to facilitate various cognitive activities are significantly more likely to experience stress related to lack of autonomy.

A small, inverse correlation between Work/Home Interface and Managing own emotions tested significant $(r=-.409, p<0.05)$. Academics who are more able to manage their own emotions are significantly more likely to experience less stress related to work/home interface.

\section{Emotional intelligence regressed onto occupational stress}

Table 6 summarizes the results of nine regression analyses. The models predicted general work stress, role ambiguity, relationships, tools and equipment, career advancement, job security, 
lack of autonomy, work/home interface and workload respectively. The predictors for each model included the subscales of emotional intelligence (utilization of emotions, managing own emotions, perception of emotions and managing others emotions). From earlier correlation matrices, the level of qualification was identified as a possible covariate and included in the regression. Gender and Race were also included in the initial regression analysis, but were excluded.

Table 6: Regression Analysis for Emotional Intelligence and Sources of Occupational Stress $(N=51)$

\begin{tabular}{|c|c|c|c|c|}
\hline Model & Predictors & Outcome & $\mathbf{R}^{2}$ & $B$ \\
\hline 1 & $\begin{array}{l}\text { Highest Qualification } \\
\text { Utilization of Emotions } \\
\text { Managing own Emotions } \\
\text { Perception of Emotions } \\
\text { Managing others Emotions }\end{array}$ & General Work Stress & $.248^{*}$ & $\begin{array}{l}-.069 \\
.152 \\
-.544^{\star *} \\
.256 \\
.163 \\
\end{array}$ \\
\hline 2 & $\begin{array}{l}\text { Highest Qualification } \\
\text { Utilization of Emotions } \\
\text { Managing own Emotions } \\
\text { Perception of Emotions } \\
\text { Managing others Emotions }\end{array}$ & Role Ambiguity & .140 & $\begin{array}{l}-.102 \\
.210 \\
-.359 \\
.053 \\
.166\end{array}$ \\
\hline 3 & $\begin{array}{l}\text { Highest Qualification } \\
\text { Utilization of Emotions } \\
\text { Managing own Emotions } \\
\text { Perception of Emotions } \\
\text { Managing others Emotions }\end{array}$ & Relationships & .230 & $\begin{array}{l}-.031 \\
.072 \\
-.145 \\
.196 \\
.033 \\
\end{array}$ \\
\hline 4 & $\begin{array}{l}\text { Highest Qualification } \\
\text { Utilization of Emotions } \\
\text { Managing own Emotions } \\
\text { Perception of Emotions } \\
\text { Managing others Emotions }\end{array}$ & Tools and Equipment & .190 & $\begin{array}{l}-.344^{*} \\
.007 \\
-.336 \\
.092 \\
-.013 \\
\end{array}$ \\
\hline 5 & $\begin{array}{l}\text { Highest Qualification } \\
\text { Utilization of Emotions } \\
\text { Managing own Emotions } \\
\text { Perception of Emotions } \\
\text { Managing others Emotions }\end{array}$ & Career Advancement & .171 & $\begin{array}{l}-.238 \\
.230 \\
-.053 \\
-.037 \\
.150\end{array}$ \\
\hline 6 & $\begin{array}{l}\text { Highest Qualification } \\
\text { Utilization of Emotions } \\
\text { Managing own Emotions } \\
\text { Perception of Emotions } \\
\text { Managing others Emotions }\end{array}$ & Job Security & $.231^{*}$ & $\begin{array}{l}.490^{\star \star} \\
.108 \\
-.024 \\
.002 \\
-.082 \\
\end{array}$ \\
\hline 7 & $\begin{array}{l}\text { Highest Qualification } \\
\text { Utilization of Emotions } \\
\text { Managing own Emotions } \\
\text { Perception of Emotions } \\
\text { Managing others Emotions }\end{array}$ & Lack of Autonomy & $.350^{\star *}$ & $\begin{array}{l}-.253 \\
.324^{*} \\
-.161 \\
.164 \\
.175 \\
\end{array}$ \\
\hline 8 & $\begin{array}{l}\text { Highest Qualification } \\
\text { Utilization of Emotions } \\
\text { Managing own Emotions } \\
\text { Perception of Emotions } \\
\text { Managing others Emotions }\end{array}$ & Work/Home Interface & $.347^{* *}$ & $\begin{array}{l}.088 \\
.317^{\star} \\
-.641^{\star \star} \\
.157 \\
.141 \\
\end{array}$ \\
\hline 9 & $\begin{array}{l}\text { Highest Qualification } \\
\text { Utilization of Emotions } \\
\text { Managing own Emotions } \\
\text { Perception of Emotions } \\
\text { Managing others Emotions }\end{array}$ & Workload & .208 & $\begin{array}{c}.128 \\
.170 \\
-.425^{\star} \\
.321 \\
.124 \\
\end{array}$ \\
\hline
\end{tabular}

${ }^{*} \mathrm{P}<.05^{* *} \mathrm{P}<.01 \quad$ Variables excluded: Gender, Race

Model 1 regressed the subscales of Emotional Intelligence and level of qualification onto General Work Stress. The model explains 24.8 per cent of the variance on general work stress 
and tested significant at a .05 alpha level. Managing own emotions significantly predicted general work stress, controlling for level of qualification, utilisation of emotions, managing others' emotions and perceiving emotions. For every one unit increase in scores for managing own emotions, there was a corresponding decrease of .544 units in general work stress controlling for the other predictors in the model. The increased ability to manage your own emotions significantly predicted decreases in general work stress controlling for the other variables in the model.

Model 6 significantly regressed the subscales of emotional intelligence and level of qualification onto Job Security $(p<0.05)$. The model explained 23.1 per cent of the variance on job security. Level of qualification significantly predicted job security controlling for utilization of emotions, managing own emotions, perception of emotions and managing others emotions at a .01 alpha level. For every one unit increase in level of qualification there is a corresponding decrease of .490 in stress related to job security controlling for other predictors in the model.

Model 7 regressed the subscales of emotional intelligence and level of qualification onto Lack of Autonomy. The model explained 35 per cent of the variance on lack of autonomy and tested significant at a .01 alpha level. Utilization of emotions significantly predicted lack of autonomy, controlling for level of qualification, managing own emotions, perception of emotions and managing others emotions at a .05 alpha level. For every one unit increase in utilization of emotions, there is a corresponding increase of .324 units in stress related to lack of autonomy controlling for the remaining predictors.

Model 8 regressed the subscales of Emotional Intelligence and level of qualification onto Work/Home interface. This model tested significant at a .01 alpha level and explains 34.7 per cent of the variance on work/home interface. Utilization of emotions $(p<.05)$ and managing own emotions $(p<.01)$ significantly predicted work/home interface, controlling for level of qualification, perception of emotions and managing others emotions. Work/home interface increased by .317 and decreased by.641 in response to a unit in utilization of emotions and managing own emotions respectively, controlling for the remaining predictors in the model.

Null findings were reported on models 2, 3, 4, 5 and 9 indicating that the combination of level of qualification and EI factors could not significantly predict Role Ambiguity, Relationships, Tools and Equipment, Career Advancement and Workload respectively.

\section{DISCUSSION}

\section{Sample characteristics}

The sample was 66.7 per cent female that reflected the gender distribution of the faculty. The 
sample composition reflected more recent gender distribution in academia and the helping professions (Riordan and Louw-Pogieter 2011). The sample comprised of a majority of academics with minority ethnic statuses e.g. Black African, Coloured and Indian.

The results indicated that 56.9 per cent of the sample occupied lecturer positions and 21.6 per cent occupied senior lecturer positions. Further, 7.8 per cent of the sample was professors, followed by associate professors (5.9\%) and associate lecturers (5.9\%). These results are reflective of the typical academic positions at HDIs, where fewer academics are positioned in higher ranks (Badat et al. 1994). Furthermore, the results revealed that 51 per cent of the total sample qualified with $\mathrm{PhD}, 45.1$ per cent with a Masters degree and 3.9 per cent with an Honours degree. These results reflect the improvements in terms of the number of doctoral academic staff, especially within HDIs. The profile in terms of ethnicity and qualifications were consistent with staff composition at HDIs (Bozalek and Boughey 2012). The results empirically support the fact that South Africa is moving towards a knowledge-based economy as the $\mathrm{PhD}$ production rate continues to increase.

\section{Occupational stress experienced among academic staff}

The frequency distributions revealed that all sources of occupational stress are being experienced in fairly similar measures as evidenced by the means. This truncated range suggests that all sources contribute to the intensity of the experience of stress in academia of this sample. Taking into consideration that no direct comparison with previous occupational stress studies can be made because different measures were used and sources were not ranked, the results indicate that occupational stress among academics are widespread. Previous studies have however reported on stressors which are of increasing concern to academics including work overload, work-life balance, job security, career advancement, lack of control and lack of resources and communication (Barkhuizen and Rothmann 2008; Gillespie et al. 2001; Tytherleigh et al. 2005; Zábrodská et al. 2018). As these sources were identified as the top stressors contributing to occupational stress, the following section will discuss how these sources differ from or align to the results obtained in this study.

A ranking of all sources of stress identified that stress related to the amount of work allocated/workload was the highest source of stress. The heavy workloads, in addition to the change in academic roles of lecturers, researcher and administrators, may have resulted from the transformations in higher education. This result is consistent with previous findings which found that academics are predominantly stressed by unmanageable workloads related to the triple demands of teaching, research and administration (Barkhuizen and Rothmann 2008; Tytherleigh et al. 2005). Jacobs and Winslow (2004) found that long working hours can 
significantly contribute to success in publishing. The interpretation is that those academics who tend to work 60 hours or more per week are more likely to publish compared to their counterparts who work less hours. Since research productivity has become a central expectation of faculty, it is understandable why many academic staff consider working longer weeks.

Longer working hours, due to increasing workloads, often blurs the boundaries that separate work from other spheres of life resulting in the conflict between work and personal life. Previous research confirmed that long working hours and heavy workloads interfered with the personal lives of academic staff. Bell, Rajendran, and Theiler (2012) reported that academics felt irritated, agitated, tense, pressured and pushed by their work demands, they experienced less work-life balance and more work-life conflict. The results of the present study similarly identified the spill over and conflict related to stress within and outside the workplace (i.e. work/home interface) as the second highest source of occupational stress in the sample.

General work stress emerged as the third highest sources of stress. General stress serves as the degree to which individuals' assess their work environments as stressful. The results reflect that workload and work-life balance is more noteworthy compared to general stress, yet general stress still appears among the top three sources of stress. Thus, academics are predominantly stressed by their workloads and interference, especially if they lack control over their demands (Barkhuizen and Rothmann 2008; Winefield et al. 2003).

Tools and equipment, career advancement and job security were less of a concern as sources of occupational stress than reported in literature (Zábrodská et al. 2018; Tytherleigh et al. 2005). Academics in this sample were less stressed about the lack of resources available to them. This result may suggest that academics within HDIs are used to using less resources as HDIs historically were less well-resourced compared to HWUs (Jansen 2003). The results further indicated that academics were less concerned about their career stability compared to the stress experienced in relation to the amount of tasks and responsibility they needed to attend to. This is not surprising, as academics in South Africa are made permanent after a probationary period of two years. Thus, academics within the sample do not face the same stressors to obtain tenure as international samples (Du Toit 2006).

\section{Emotional intelligence among academic staff}

The findings revealed that managing your own emotions was the highest ranked EI capability. This suggests that academic staff have the capacity to manage their emotions when stressed. Being an academic, entails a high human interaction which requires awareness of and the ability to effectively regulate strong emotions (El-Sayed et al. 2014). Academics in health professions have to use emotion regulation skills to establish therapeutic relationships with their patients 
and clients, manage emotions in themselves to prevent vicarious traumatisation and burnout, provide clinical supervision and mentoring, and to maintain an empathic stance towards their work (Romanelli, Cain and Smith 2006). Thus, they are likely to possess emotion regulation skills. Littlejohn (2012) concluded that managing one's own emotions was a key component in the lives of health profession academics. The results of the current study empirically support the assumption that academics in health professions are emotionally skilled individuals who use EI capabilities to regulate their own emotions.

Perception of emotion and managing the emotions of others jointly ranked second in the frequency distribution. This finding suggests that academics have the capacity to recognise their own emotions and those of others through cues such as behaviour, facial expressions and language. This process allows academics to assess potentially challenging situations and intervene effectively and preventatively (Ashkanasy and Daus 2002). The results indicated that academics can manage the emotions of others by regulating negative emotions such as anxiety and frustration and enhancing pleasant ones. With the use of these skills, academics are likely to build successful relations with their colleagues, and manage conflict and stress successfully (Brackett, Rivers and Salovey 2011).

The results further revealed that fewer academics utilize their emotions towards better job performance, as evidenced by the means (ranked $3^{\text {rd }}$ ). When defining utilization of emotions, we are focusing on the person's ability to use those emotions to facilitate cognitive activities such as problem solving (Jude 2011). In the case of the academic profession, emotions may direct attention to important information and may encourage specific problem-solving approaches when academics encounter difficult situations. However, it is observed that fewer academics engage in this process for the reason that other skills may take precedence to enhance job performance before utilization of emotion.

\section{Associations between demographics and occupational stress}

The correlations revealed a gendered pattern to occupational stress related to work/home interface. Female academics experienced more pressure trying to actualize themselves in their work place while continuing to carry the major responsibility at home and in the family. This pattern resonated with the literature reporting that female academics accommodate the demands of their career through outside assistance for household responsibilities (Naidoo and Jano 2002). Family and personal obligations coupled with greater responsibilities for work related duties mean that women have to negotiate maternal or parental responsibilities with stringent academic demands (Higgins, Duxbury and Lyons 2010). Recent research has highlighted that women in academic positions experience higher levels of burnout than their male counterparts 
(Zábrodská et al. 2018). Addittionally, a systematic review conducted by Watts and Robertson (2011) reported that female teaching staff report higher levels of emotional exhaustion, which may be due to these multiple roles and their emotional demands.

The results show that junior academics experienced more stress related to tools and equipment. This was consistent with literature reporting that higher levels of stress in early career academics or recent appointees due to unfamiliarity with organizational functioning and clarity about their roles as academics (Frantz and Smith 2010). The adjustment period is stressful due to pressure to develop an understanding of the organization, their tasks and the tools and skills needed to perform effectively (Smith and Boyd 2012).

An association was found between years in academia and stress related to job security that corresponds with previous research. Academics within the early career phase are in vulnerable positions. The demands placed on early career academics often result in negative outcomes including stress and disempowerment (Murray, Stanley and Wright 2014). Similarly, new academics experience several competing demands to adjust and to perform (Miller, Taylor and Bedeian 2011).

The results revealed a racialized pattern to the experience of job security and lack of autonomy as sources of occupational stress. Minority ethnic groups were more likely to experience these sources of stress. The results were consistent with literature indicating higher levels of stress related to job insecurity and lack of independence or perceived powerlessness amongst Black academics (Netswera, Rankhumise and Mavundla 2005). The reported racial patterns are vestiges of Apartheid.

The results identified a significant association between academic status and stress related to career advancement. Literature has highlighted that academic staff in junior positions found career development to be a source of stress (Archibong, Bassey and Effiom 2010). More senior academics including those with doctorates are less likely to experience stress related to career advancement. As mentioned before, policy changes prioritize completion of $\mathrm{PhDs}$ to achieve transformational goals and advance careers that result in increased stress.

\section{Associations between demographics and El}

A gendered pattern was identified on emotion management and gender. Female academics were more likely to use emotional strategies to become aware of, maintain, regulate or change emotional experience or expression. The results echoed the literature reporting that women have higher EI and more complex emotion knowledge (Watts and Robertson 2011), whereas men are more emotionally intense, emotionally expressive and skilled in using nonverbal cues related to emotion (Joseph and Newman 2010). Women were also found to better manage 
feelings of anger, contempt, and disgust, whereas men better managed the emotions of fear and surprise. The results imply that women in academic settings are more likely to manage or regulate emotions.

A racialised pattern to managing emotions was identified. The results indicate that there is a tendency amongst academics of minority ethnic status to engage more in self-management and management of the emotions of others. There is a substantial lack of research regarding race and emotional intelligence. However, this finding resembles the surveillance reported by professionals of minority statuses when working in competitive environments (Stanley 2006).

A negative association was found between managing others emotions and level of qualification. The results suggest that academics with higher qualifications may be more focused on organizational outcomes, managerial tasks and research focused, whilst academics with lower qualifications are more involved with students. Thus, academics with lower qualifications are most likely to be in situations that require them to manage the emotions of others. The finding resonated with Matthews and Zeidner (2000) who reported that academics with lower qualifications are more likely to manage the emotions of others.

\section{Predictive relationships between El and occupational stress}

Mixed results emerged for the hypothesized predictive relationship between EI and sources of occupational stress. The combination of EI and level of qualification could significantly predict four sources of occupational stress, namely, general work stress, job security, lack of autonomy and work/home interface. However, the combination of EI and level of qualification were not able to significantly predict stress related to role ambiguity, relationships, tools and equipment, career advancement and workload.

In model 1, managing own emotions emerged as a significant predictor of general work stress controlling for level of qualification, using emotions, perceiving emotions and managing others emotions. The ability to manage one's own emotions can significantly predict the stress experienced in relation to one's work. Emotion management involves the skill of influencing which emotions are experienced, when they are experienced and how they are expressed (Szczygiel, Buczny and Bazińska 2012). Health profession academics that possess the skill of managing their own emotions are less likely to experience stress related to their work. In other words, they are most likely to regulate their emotions when experiencing a stressful situation. This could be applied to academics in the academic environment and could result in an increase in constructive self-evaluations (Gorgens-Ekermans and Brand 2012). As a result, academics could have increased feelings related to competency, achievement and confidence in their ability to perform well, consequently decreasing occupational stress. Academics who are 
capable of regulating how they feel or change the feelings they show are most likely to interact with students and colleagues in an effective way.

In model 6, level of qualification was a significant predictor of job security controlling for EI. The results suggest that academics who have obtained higher qualifications, such as $\mathrm{PhDs}$, experience less stress concerning job security. Within academia, job security is guaranteed when academics have obtained tenure. Essentially, higher qualified academics have most likely demonstrated mastery in teaching and have actively engaged in publishing research, thus receive tenure and are guaranteed permanent employment within higher education institutions. Academics with a lower qualification may still need to work towards permanence or probation requirements, consequently they are more vulnerable as job security is not guaranteed. Less qualified academics are still working towards attaining career aspiration and career development that were identified as amongst the most stressful factors experienced by academic staff (El-Sayed et al. 2014).

EI was not a significant predictor of stress related to job security controlling for level of qualification. This means that irrespective of whether academics were emotionally intelligent, their qualifications emerged as a stronger predictor of stress related to job security. This also resonated with the current reality in the South African landscape that emphasized completion of higher degrees for personal promotion and transformation at a macro and institutional level.

In model 7, using emotions was found to be a significant predictor of stress related to lack of autonomy, controlling for level of qualification, managing own and others' emotions and perception of emotions. Academics who use emotions to perform effectively at their work are more capable of working independently, thus experience less stress regarding job autonomy. This finding resonated with past research, for example Kim et al. (2009) reporting that emotionally intelligent individuals were most likely able to make independent decisions, because they use their emotions towards better job performance.

Two significant predictors were found in model 8. The one focused on managing one's own emotions and this emerged as a significant predictor of stress related to work/home interface controlling for level of qualification, using emotions, perceiving emotions and managing others emotions. These findings empirically support the notion that managing one's own emotions predicts the amount of stress experienced related to work/home conflict. Using emotions also emerged as a significant predictor of work/home interface controlling for the remaining predictors. Surprisingly, academics that use their emotions were most likely to experience stress related to work/home interface as this could lead to emotional exhaustion or burnout. Furthermore, health professions are generally more aware and able to use their emotions at home and work, thus this predisposes them to emotional exhaustion. Health 
professionals also are more reflective of the impact of career demands on the family life and therefor are more likely to engage with this as source of stress.

\section{CONCLUSION}

Based on our South African history and the universal forces, the pressure for making a difference in higher education is real. Government policies has put pressure on universities to restructure during the democratic era (Waghid 2002). Transformation and change resulting from policy implementation is a leading source of occupational stress among academics (Fourie 1999; Mapesela and Hay 2006). Academics face increasing demands related to their role as knowledge producers and producers of knowledge producers.

Academia is a stressful profession for this sample. Academics experienced their workloads as a major source of occupational stress that was mainly attributed to transformations and the work environment. This study underscored that the historical nature of the university still manifest in patterned ways along gender, race and professional status in the occupational stress academics experience. The results revealed that academics possess emotional intelligence skills allowing them to cope effectively with occupational stress. Health profession academics are very capable of managing and regulating their emotional experiences and expressions when confronted with challenging situations.

Results indicated that EI provided participants the ability to use emotional information to guide their judgment in dealing with particular sources of occupational stress. The predictive relationships between variables further substantiate that EI in combination with level of qualification can significantly predict certain sources of occupational stress among academics.

\section{Significance of the study}

The present study provided insight into the possible issues faced by academics and highlighted the need to address occupational stress within higher education. This study provided empirical support for the notion that academics experience moderate to high levels of occupational stress. Emotional intelligence emerged as an important factor in the experience and management of occupational stress. This study provided a platform to engage with the experience and management of occupational stress among Health Profession academics at a HDI.

\section{Limitations of the study}

Profiles for Occupational stress and EI were ranked, and the degree of the difference/ variation within the sample could not be determined. Self-report measures have an inherent disadvantage in that the respondent may rush through the questionnaire or provide socially desirable answers. The effect sizes were small which requires caution in the interpretation of results. 


\section{Recommendations}

A further exploration of emotional management or regulation among academic staff was recommended. Future research could consider replication with samples from more universities.

\section{REFERENCES}

Adeyemo, D. A. and B. Ogunyemi. 2005. Emotional intelligence and self-efficacy as predictors of occupational stress among academic staff in a Nigerian university. Nigerian Journal of Clinical and Counselling Psychology 7(2): 135-156.

Archibong, I. A., A. O. Bassey and D. O. Effiom. 2010. Occupational stress sources among university academic staff. European Journal of Educational Studies 2(3).

Armstrong, Andrew R., Roslyn F. Galligan and Christine R. Critchley. 2011. Emotional intelligence and psychological resilience to negative life events. Personality and Individual Differences 51: 331-336.

Ashkanasy, Neal M. and Catherine S. Daus. 2002. Emotion in the workplace: The new challenge for managers. The Academy of Management Executive 16(1): 76-86.

Atindanbila, Samuel. 2011. Percieved stressors of lecturers at the University of Ghana. Journal of Emerging Trends in Educational Research and Policy Studies 2(5): 347-354.

Badat, S., F. Barron, G. Fisher, P. Pillay and H. Wolpe. 1994. Differentiation and disadvantage: The historically Black universities in South Africa . Education Policy Unit, University of the Western Cape, Bellville.

Barkhuizen, N. and S. Rothmann. 2008. Occupational stress of academic staff in South African higher education institutions. South African Journal of Psychology 38(2): 321-336.

Bar-On, R. 2010. Emotional intelligence: An integral part of positive psychology. Psychological Society of South Africa 40(1): 54-62.

Bauwens, R., M. Audenaert, J. Huisman and A. Decramer. 2017. Performance management fairness and burnout: implications for organizational citizenship. Studies in Higher Education. doi:10.1080/03075079.2017.1389878.

Bell, Amanda S., Diana Rajendran and Stephen Theiler. 2012. Job stress, wellbeing, work-life balance and work-life conflict among Australian academics. Electronic Journal of Applied Psychology 8(1): 25-37.

Bezuidenhout, Adele and Frans Cilliers. 2010. Burnout, work engagement and sense of coherence in female academics in higher education institutions in South Africa. South African Journal of Industrial Psychology 36(1): 1-10.

Blix, A. G., R. J. Cruise, B. M. Mitchell and G. G. Blix. 1994. Occupational stress among university teachers. Educational Research:157-169.

Bozalek, Vivienne and Chrissie Boughey. 2012. (Mis)framing higher education in South Africa. Social Policy and Administration 46(6): 688-703.

Brackett, Marc A., Susan E. Rivers and Peter Salovey. 2011. Emotional intelligence: Implications for personal, social, academic and workplace success. Social and Personality Psychology Compass 5: $88-103$.

Carver, Charles and Jennifer Connor-Smith. 2010. Personality and coping. Annual Review of Psychology 61: 679-704.

Cherniss, C. 2010. Emotional intelligence: Toward clarification of a concept. Industrial and Organizational Psychology 3: 110-126.

Darabi, M., A. Macaskill and L. Reidy. 2017. Stress among UK academics: identifying who copes best. 
Journal of Further and Higher Education 41(3): 393-412. doi:10.1080/0309877X.2015.1117598.

De Bruin, Gideon P. and Nicola Taylor. 2005. Development of the sources of work stress inventory. South African Journal of Psychology 35(4): 748-765.

Department of Science and Technology. 2007. Innovation towards a knowledge-based economy. http://www.esastap.org.za/download/sa_ten_year_innovation_plan.pdf.

DST see Department of Science and Technology

Du Plessis, Graham, Larise du Plessis and Carol Saccaggi. 2013. The lived experiences of professional clinical psychologists who recently started a new academic career. The Indo-Pacific Journal of Phenomenology 13(2): 1-12.

Du Toit, Andre. 2006. Professionalising tenure: An academic freedom perspective. Paper presented at Rhodes University.

El-Sayed, S. H., H. H. A. El-Zeiny and D. A. Adeyemo. 2014. Relationship between occupational stress, emotional intelligence and self-efficacy among faculty members in faculty of nursing Zagazig University, Egypt. Journal of Nursing Education and Practice 4(4): 183-194.

Fako, T. 2010. Occupational stress among university employees in Botswana. Journal of Social Sciences $15(3)$.

Fernandez, Claudia S. 2007. Emotional intellignece in the workplace. Journal of Public Health Management 13(1): 80-82.

Fourie, Magda. 1999. Institutional transformation at South African universities: Implications for academic staff. Higher Eudcation 38: 275-290.

Frantz, J. and M. R. Smith. 2010. Staff development strategies for publication in the Faculty of Community and Health Science at UWC. Journal of Community \& Health Sciences 5(1): 53-62.

Frantz, J. and M. R. Smith. 2013. Exploring the subjective experiences of allied health professionals in their transition from clinical educators to academia: Barriers and facilitators to successful transition. African Journal of Health Professions Education 5(1): 37-41.

Gillespie, N. A., M. Walsh, A. H. Winefield, J. Dua and C. Stough. 2001. Occupational stress in universities: Staff perceptions of the causes, consequences and moderators of stress. Work and Stress 15(1): 53-72.

Gohm, C., G. Corser and D. Dalsky. 2005. Emotional intelligence under stress: Useful, unnecessary, or irrevelant? Personally and Individual Differences 39: 1017-1028.

Gorgens-Ekermans, G. and T. Brand. 2012. Emotional intelligence as a moderator in the stress-burnout relationship: a questionnaire study on nurses. Journal of Clinical Nursing 21: 2275-2285.

Gornall, L. and J. Salisbury. 2012. Compulsive working, hyperprofessionality and the unseen pleasure of academic work. Higher Education Quarterly 66(2): 135-154.

Hay, D. and M. Monnapula-Mapesela. 2009. South African higher education before and after 1994: A policy analysis perspective. In Higher Education in South Africa, by E Blitzer, 3-20. Stellenbosch: Sun Press.

Higgins, C. A., L. E. Duxbury and S. T. Lyons. 2010. Coping with overload and stress: Men and Women in Dual-earner families. Journal of Marriage and Family 72(4): 847-859.

Jacobs, J. A. and S. E. Winslow. 2004. Overworked Faculty: Job stresses and family demands. The Annals of the American Psychology 596: 104-129.

Jansen, J. D. 2003. On the state of South African universities. South African Journal of Higher Education 17(3): 9-12.

Joseph, D. L. and D. A. Newman. 2010. Emotional intelligence; an integrative meta-analysis and cascading model. Journal of Applied Psychology 95(1).

Jude, Akomolafe M. 2011. Emotional Intelligence, gender and occupational stress among secondary school teachers in Ondo State, Nigeria. Pakistan Journal of Social Sciences 8(4): 159-165.

Kim, Tae-Yeol, Daniel M. Cable, Sang-Pyo Kim and Jie Wang. 2009. Emotional competence and work 
performance: The mediating effect of proactivity and the moderating effect of job autonomy. Journal of Organizational Behaviour 30: 983-1000.

Kinman, G. and F. Jones. 2003. Running up and down the escalator: stressors and strains in UK academics. Quality in Higher Education 9: 21-38.

Kotecha, K., W. Ukpere and M. Geldenhuys. 2014. Technology and work-life conflict of academics in South African higher education institution. Mediterranean Journal of Social Sciences 5(2): 629641.

Littlejohn, Patricia. 2012. The missing link: Using emotional intelligence to reduce workplace stress and workplace violence in our nursing and other health care professions. Journal of Professional Nursing 28: 360-368.

MacCann, Carolyn, Gerard J. Fogarty, Moshe Zeidner and Richard D. Roberts. 2011. Coping mediates the relationship between emotional intelligence (EI) and academic development. Comtemporary Educational Psychology 36: 60-70.

Mapesela, Mabokang and Driekie Hay. 2006. The effect of change and transformation on academic staff and job satisfaction: A case of a South African University. Higher Education 52: 711-747.

Mark, Goerge and Andrew P. Smith. 2012. Effects of occupational stress, job characteristics, coping and attributional style on the mental health and job satisfaction of university employees. Anxiety, Stress and Coping 25(1): 63-78.

Matthews, G. and M. Zeidner. 2000. Emotional intelligence, adaptation to stressful encounters and health outcomes. In The handbook of emotional intelligence: Theory, development, assessment, and application at home, school, and in the workplace, ed. by R. Bar-On and J. D. A. Parker, 459489. San Francisco, CA: Jossey-Bass.

Miller, A. N., S. G. Taylor, and A. G. Bedeian. 2011. Publish or perish: Academic life as management faculty live it. Career Development International 16(5): 422-445.

Ministry of Education. 2001. National Plan for Higher Education. Pretoria. http://www.unisa.ac.za/ contents/projects/docs/National\%20Plan\%20Higher\%20Education.pdf

Montes-Berges, B. and J. M. Augusto. 2007. Exploring the relationship between percieved emotional intelligence, coping, social support and mental health in nursing students. Journal of Psychiatric and Mental Health Nursing 14: 163-171.

Murray, Carolyn, Mandy Stanley and Shelley Wright. 2014. The transition from clinician to academic in nursing and allied health: A qualitative meta-synthesis. Nurse Education Today 34: 389-395.

Naidoo, A. V. and R. Jano. 2002. Role salience f dual-career women managers. South African Journal of Industrial Psychology 28(3): 69-74.

National Development Plan 2030. 2012. Our future - make it work. Pretoria: National Planning Commission. http://www.gov.za/sites/www.gov.za/files/Executive\%20Summary-NDP\%202030 \%20-\%20Our\%20future\%20-\%20make\%20it\%20work.pdf

Netswera, F. G., E. M. Rankhumise and T. R. Mavundla. 2005. Employee retention factors for South African higher education institutions: A case study. South African Journal of Human Resource Management 3(2): 36-40.

Nikolaou, I. and I. Tsaousis. 2002. Emotional intelligence in the workplace: Exploring its effects on occupational stress and organisational commitment. The International Journal of Organisational Analysis 10(4): 327-342.

O’Connell, B. 2011. Celebrating 50 years of excellence. http://mg.co.za/article/2011-02-18-celebrating50-years-of-excellence

Pau, Allan K. and Ray Croucher. 2003. Emotional intelligence and percieved stress in dental undergraduates. Critical Issues in Dental Education 67(9): 1023-1028.

Pienaar, Cobus and Coen Bester. 2009. Addressing career obstacles within a changing higher education work environment: perspectives of academics. South African Journal of Psychology 39(3): 376385. 
Por, J., L. Barriball, J. Fitzpatrick and J. Roberts. 2011. Emotional intelligence: Its relationship to stress, coping, well-being and professional performance in nursing students. Nurse Education Today 31: 855-860.

Riordan, Sarah and Joha Louw-Pogieter. 2011. Career success of women academics in South Africa. South African Journal of Psychology 41(2): 157-172.

Romanelli, F., J. Cain and K. Smith. 2006. Emotional intelligence as a predictor of academic and/or prefessional success. American Journal of Pharmaceutical Education 70(3): 1-10.

Rosenthal, T. and A. Alter. 2012. Occupational stress and hypertension. Journal of the American Society of Hypertension 6(1): 2-22.

Schutte, N. S., J. M. Malouff, L. E. Hall, D. J. Haggerty, J. T. Cooper, C. J. Golden and L. Dornheim. 1998. Development and validation of a measure of emotional intelligence. Personality and Individual Differences 25: 167-177.

Schutte, N. S., J. M. Malouff and N. Bhullar. 2009. The Assessing Emotions Scale. In The Assessment of Emotional Intelligence, by C. Stough, D. Saklofske and J. Parker, 119-135. New York: Springer Publishing.

Smith, Caroline and Pete Boyd. 2012. Becoming an adacemics: the reconstruction of identity by recently appointed lecturers in nursing, midwifery and allied health professions. Innovations in Education and Teaching International 49(1): 63-72.

Stanley, C. A. 2006. Coloring the academic landscape: Faculty of color breaking the silence in predominanatly White colleges and universities. American Educational Research Journal 43(4): 701-736.

Survey Monkey. 2016. Survey Monkey. https://www.surveymonkey.com/mp/take-a-tour/?ut_ source $=$ header.

Szczygiel, D., J. Buczny and R. Bazińska. 2012. Emotion regulation and emotional information processing: The moderating effect of emotional awareness. Personality and Individual Differences 52: 433-437.

Tytherleigh, M. Y., C. Webb, C. L. Cooper and C. Ricketts. 2005. Occupational stress in UK higher education insitutions: A comparative study of all staff categories. Higher Education Research and Development 1: 41-61.

Waghid, Y. 2002. Knowledge production and higher education transformation in South Africa: Towards reflexivity in university teaching, research and community service. Higher Education 43: 457488.

Watts, J. and N. Robertson. 2011. Burnout in university teaching staff: a systematic review. Educational Research 53(1): 33-50.

Zábrodská, Kateřina, Jiř́i Mudrák, Iva Šolcová, Petr Květon, Marek Blatný and Kateřina Machovcová. 2018. Burnout among university faculty: The central role of work-family conflict. Educational Psychology 38(6): 800-819. doi:10.1080/01443410.2017.1340590 